\title{
Modeling and Supervision of Natural Gas Station in a Thermal Power Plant
}

\author{
Lakhoua M.N. \\ Research Laboratory EI\&TIC \\ National Engineering School \\ of Carthage, ENICarthage \\ University of Carthage \\ lnajeh@yahoo.fr
}

\begin{abstract}
This paper presents the need for structured analysis and real time (SA-RT) method of control-command applications in a thermal power plant (TPP) using a supervisory control and data acquisition systems (SCADA). Then, the architecture of a SCADA system in a TPP in Tunisia is presented. A significant example of a control-command application in a TPP in Tunisia is presented. It is about the natural gas station of the TPP. Then an application of a structured analysis method in a TPP, generally used in industry, on the basis of the SA-RT formalism is presented. In fact, different modules are presented: Context Diagram, Data Flows Diagram, Control Flows Diagram, State Transition Diagram, Timing Specifications and Requirements Dictionary. Finally, this functional and operational analysis allows us to assist the different steps of the specification, the programming and the configuration of a new tabular in a SCADA system of the natural gas station.
\end{abstract}

Keywords-SCADA specification; SA-RT method; natural gas station; thermal power plant.

\section{INTRODUCTION}

In our days in different industrial areas it become very important to analysis, control and supervise the production systems. Supervisory control and data acquisition systems (SCADA) have become popular than an other systems to establish the efficient monitoring and control of distributed remote equipments [1].

The SCADA system habitually consists of the following subsystems [2-3]:

- A Man-Machine Interface (MMI) is the tools which presents process data to a human operator, and through this, the human operator monitors and controls the process.

- A supervisory system, acquiring data on the process and giving commands to the process.

- A Remote Terminal Units (RTU) linking to sensors in the process, converting sensor signals to digital data and giving digital data to the supervisory system.

- A communication infrastructure connecting the supervisory system to the RTU.

SCADA systems can be found in risky infrastructures for example power grid systems and power plants, gas, oil and water distribution systems, structure monitoring, production systems for food, cars, ships and other products [4-6].

In industrial plants, the supervision systems implemented in SCADA software, must assume, at least, the next three main tasks: monitoring, control and fault tolerance.

Indeed, the majority control actions are performed automatically by RTU or by programmable logic controllers (PLC) [7-11]. Multitude control functions are habitually limited to basic overriding or supervisory level intervention.

For instance, a PLC can control the flow of water cooling through element of an industrial process, but the SCADA system can allow operators to change the set points for the flow, and permit alarm conditions, such as loss of flow and high temperature, to be displayed and recorded. The feedback control loop passes through the RTU or PLC, while the SCADA system monitors the overall performance of the loop

The aim of this article is to explain benefit of the use of structured analysis and real time analysis (SA-RT) for system specification. The next section briefly presents SCADA system in a thermal power plant (TPP) and an example of a controlcommand application. Finally, a case study of the SA-RT analysis of a natural gas station in a TPP using a SCADA system is presented and discussed.

\section{PRESENTATION OF A SCADA SYSTEM AND A NATURAL GAS STATION}

An example of a SCADA system of a thermal power plant (TPP) Tunisia is constituted of the following elements [12-14]:

- A plate of terminal board;

- FBM (Field Bus Module);

- FCM (Field Bus Communication Module);

- CP60 (Control process);

- DNBT (Dual Node Bus base_T interface);

- AW (Work Station Processor);

- WP (Application Work Station).

In a TPP, there are many tools used by the SCADA system (Fig.1), for instance: 
- SYS MON: system monitor that supervises the good working of all the facilities of the system. FOX DRAW: creator of tabular.

- FOXVIEW: interfacing operator to visualize the tabular with a slim rod to activate the main functions of the SCADA system.

- FOX SELECT: software permitting to reach the various elements of the hierarchy of the data base of the CP60.

- ICC (Integrated Control Configuration): software permitting to produce and to configure programs residing in the CP60.

- AIM HISTORIAN: software permits to collect, to organize and to protect data for storage, it also permits to configure features of points to archive, as messages partners to events.

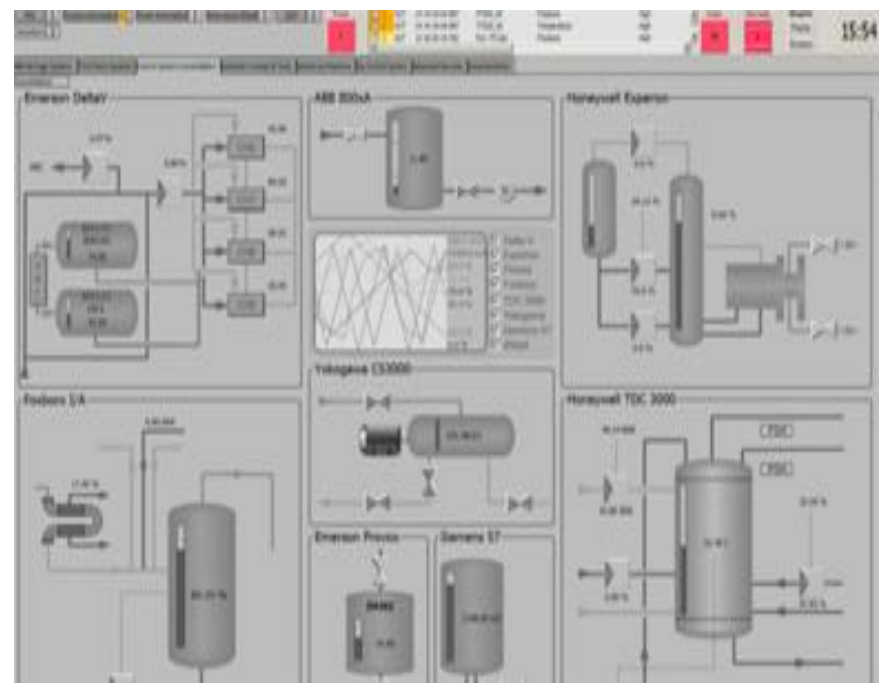

Fig. 1. Architecture of the SCADA system of a TPP

In order to present a control - command application in a TPP, we study here a significant example is the natural gas station.

In fact, in the Tunisian electrical system, the different generation sources are: hydroelectric, co-generation, renewable (biomass, solar and wind), natural gas thermal power, and others including diesel, oil and coal. The decision to invest in power generation projects, especially in natural gas (NG) thermal power generation, involves a series of issues and challenges. In fact, the real need for thermal power capacity is determined by the combination of energy supply and demand curves [15-17].

NG is the fastest growing primary energy source in the world. It is the more used than fuels and coal in the TPPs. It is more manageable and presents dangers and a bigger explosion risks. The exploitation of the NG requires a structure of equipment, of instruments and an automatic control (Fig.2).

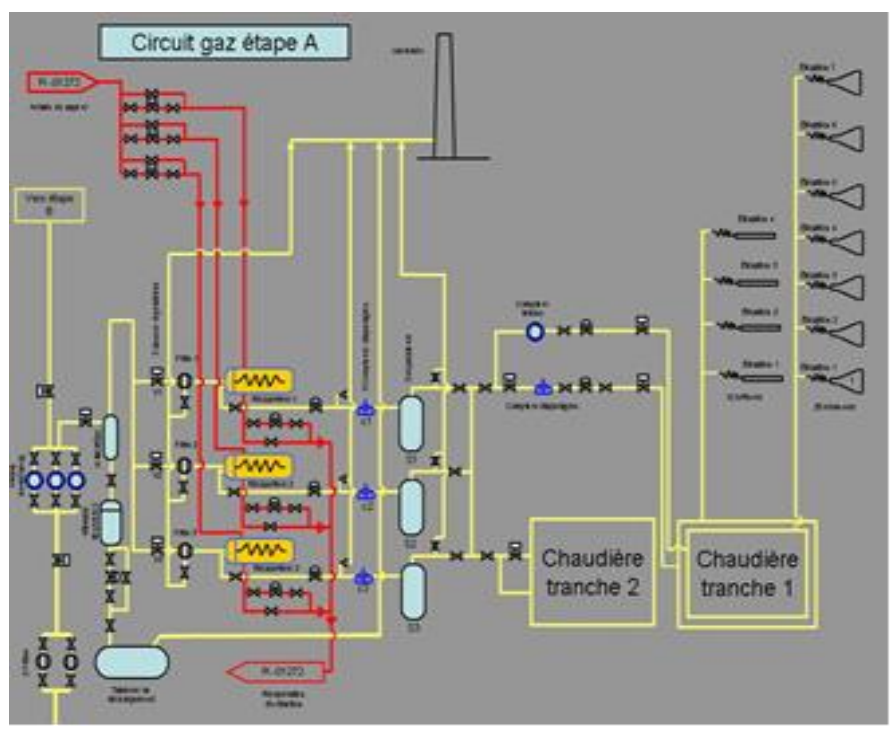

Fig. 2. Display of the NG station of the TPP

One of the main features of the utilization of the NG in a TPP is constituted by the importance of volumes clear soups. The research of precision in the measures volumes of gas became then as much for the supplier as for the consumer a necessity.

The first interest of the precise numbering of gas is the control of invoicing. The second interest, own to the TPP is the establishment of the complete economic control of the power plant. The third interest is to have a picture of the load produced currently; the important debits are in general measured by the volumetric counters.

The Center of Production of Electricity of Rades (C.P.E.R) is nourished in NG from the Tunisian network of distribution. In fact, the gas undergoes several operations of preparation (Fig.2) before being introduced in the steam generator, it must be filtered, rehash, relaxed and counted.

The pressure of the NG nourishing burners and lighters vary according to the rate of combustion asked of 1.5 to 2.2 bars, gas arrives to the C.P.E.R to a pressure understood between 15 and 20 bars. It is therefore necessary to loosen it in order to have a neighboring pressure of 4 bars before the regulating floodgate. A second distinct relaxation for each generator of steam adjusting the pressure of the order of two bars has the uphill of the regulating floodgate of debit of NG.

The expansion of gas can provoke, according to types of regulator and the conception of relaxation stations, of noises that are transmitted and amplified sometimes by pipelines, can reach some inadmissible levels for the man and for the good holding of the material. In the critical cases, one decreases the importance of this phenomenon while immediately choking noises in mufflers rooms after regulators. A regulation of arrival of the calorific flux (fluid of heating) is necessary in order to maintain a temperature understood between $15^{\circ} \mathrm{C}$ and $20^{\circ} \mathrm{C}$ after relaxation. This temperature corresponds to the one of the numbering. 
A separator, placed in head of the station, assures a first elimination of foulness can be transported by the NG generally the separator is slim of a decantation pot. Filters assure the final operation. These filters have an important role in beginning of exploitation. Dusts and oxide of iron contents in pipelines of gas are progressively driven toward the primary station of relaxation.

All the time, in facilities where gas circulates with big speed these filters are indispensable of the fact of the continuous practice of oxides that would risk to damage regulators and burners. Floodgates of security are used in facilities to multiple lines, they are placed upstream of every regulator, and they serve to isolate the trigger line in the event of a defect. The floodgate of security is ordered by the pressure of the gas of the circuit downstream, therefore the closing of this floodgate depends solely on the order of pressure of declenchment of the floodgate and must make him in consideration of the influence of losses of load and the possible state of the regulator according to the debit of NG.

The objective of the SCADA system of the C.P.E.R is to collect data instantaneously of their sites and to transform in signals and numeric impulse and to send them through the network of communication toward the main and secondary stations. Indeed, the received data by the SCADA system only present $20 \%$ of the existing data totality.

In order to facilitate the different steps of the programming and the configuration of the tabular of the NG station, we presented an SA-RT analysis.

\section{SA-RT FORMALISM}

In this paragraph, the results of the SA-RT analysis of the NG station using a functional and operational SA-RT method are presented.

\section{A. SA-RT formalism}

There are numerous graphical methods generally used in industry. Two of the most important methods are SA-RT and Statecharts.

The first method is SA-RT which is a short name for Structured Analysis Method with extensions for Real Time [18-20]. The model is represented like a hierarchical set of diagrams that includes data and control transformations (processes). In fact, the control transformations are specified using State Transition diagrams, and the events are represented by control flows [21-26].

The second method is Statecharts which is a paradigm for specification of real time systems based on graphical and state. The system is represented like a set of hierarchical states as an alternative of processes. Every state can be decomposed into sub states and so on. The Statecharts notation is more condensed than the SA-RT notation and has been formally defined.
As a result, SA-RT is a complex method for system analysis and design. This is one of the most often used design method in technical and real- time oriented applications adopted by various Case-Tools [27-23]. It is a graphical, hierarchical and implementation autonomous method for topdown development (Fig.3).

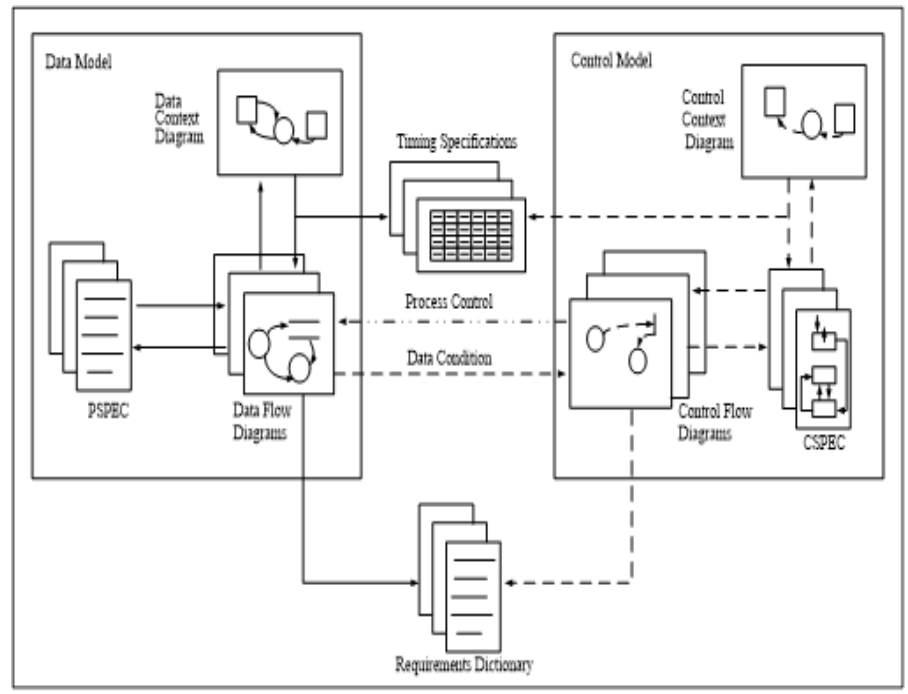

Fig. 3. Organization of an SA-RT model

SA-RT method enables us to recognize an entrance and an exit of data in an algorithm or a computer program [24-41]. It is divided in three modules: Context Diagram (CD), Data Flows Diagram (DFD) and Control Flows Diagram (DFC). Each module includes in its graphic interpretation special symbols.

Indeed, the Context Diagram in the SA-RT method is going to enables us to recognize a process in a program concerning the entered and exits of data. This process can have different units. This process will be able to be identified per seconds, in term of constant or variable but as this process will be able to be material type (process interfacing).

In the Context Diagram of the SA-RT method, different symbols are used:

- The terminator is the element in end that encloses the action.

- The data flow is the final element that opens up on a last action.

In fact, the termination is usually a direct tie between a terminator and the process The control flow is usually a tie back of the process toward the terminator. It can be a main element of the process.

\section{B. Results of the SA-RT analysis}

The SA-RT method allows a functional as well as a temporalanalysis. Then, the case study of NG station is analyzed according to the SA-RT formalism.

After SA-RT analysis, four diagrams are presented as follows : Context diagram of the natural gas station; Data 
flow diagram of the natural gas station; Control flow diagram of the natural gas station; State-transition diagram of the natural gas station.

Figure 4 shows the context diagram of the NG station. In fact, the context diagram is constituted of one functional process "To pilot the NG station " and six terminators (Temperature sensors of the NG, Pressure sensors of the NG, Debit Sensors of the NG, Operator, SCADA and Actuators of the NG).

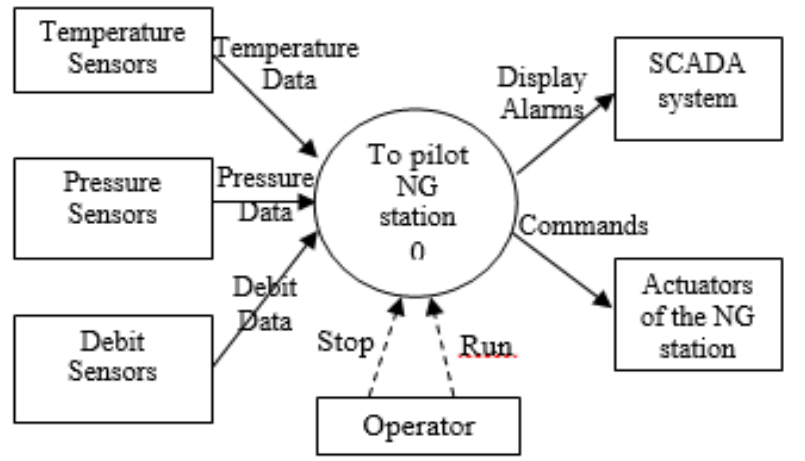

Fig. 2. Context diagram of the SA-RT model of the NG station.

The context diagram defines completely the interface between the designer and the client, that is, to provide or generate data in order to display these data on the displays of the TPP.

Figure 5 shows the Control flow diagram of the SA-RT model that includes the control feature to the data flow diagram elaborated. In fact, the implementation of the process of monitoring at the level of preliminary diagram can state the execution or the sequence of the functional processes.

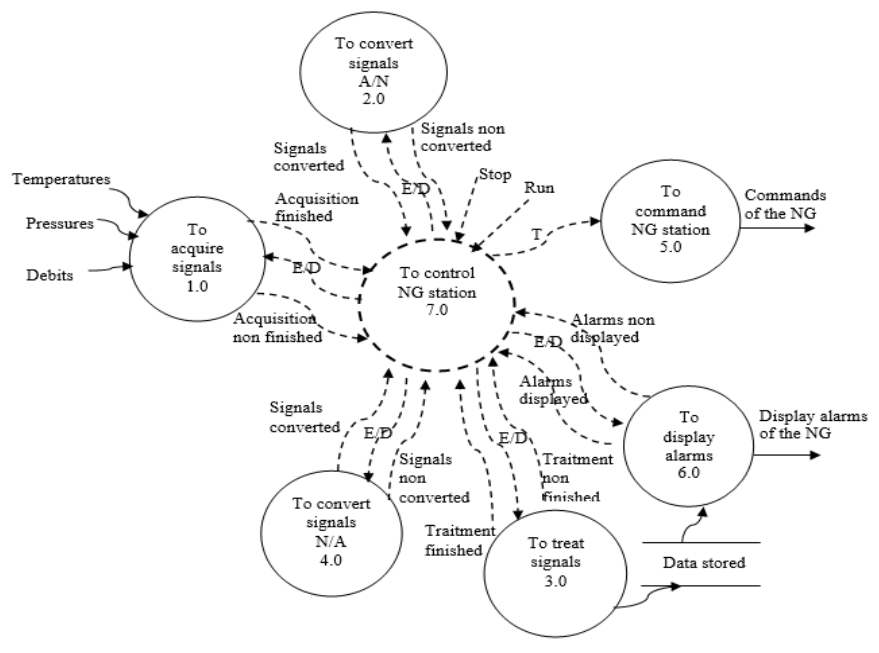

Fig.5. Control Flows Diagram of the NG station

Figure 6 shows the state-transition diagram of the SA-RT model of the NG station of the TPP.

The potential uses for the SA-RT model are the design of a monitoring display and a diagnosis display. For the design of a monitoring display, the preliminary data flow diagram of the SA-RT model supplies a comprehensive view of the system.

Indeed, information relative to all processes represented through this stage should appear in a monitoring display.

For the design of hierarchical diagnosis display, each data flows diagram of the SA-RT model constitutes an image at a given abstraction stage. Therefore, each of these data flows diagrams gives a less or more detailed vision. In fact, the designer defines the objectives for each display and can provide the necessary information by a particular data flows diagram can provide.

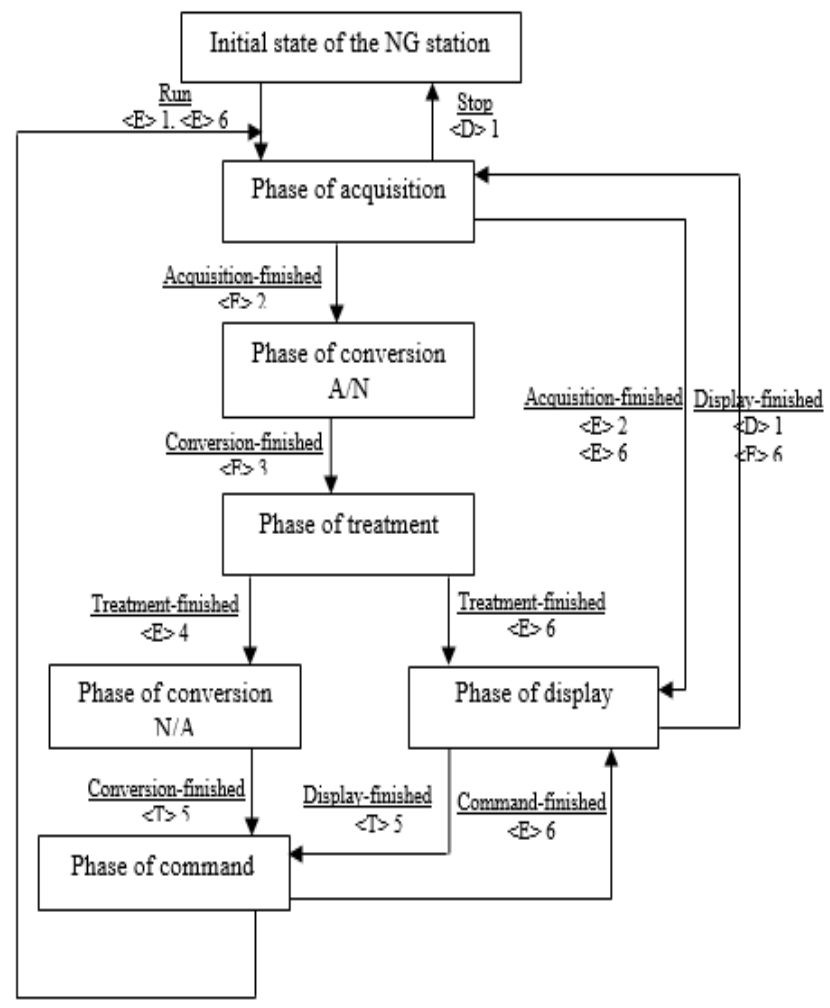

Fig.6. State/Transition diagram of the NG station.

\section{CONCLUSION}

In this paper, the functionality of a SCADA system is presented on the one hand, and a control-command of the natural gas station using the SA-RT method is analyzed, on the other hand. In fact, it is very important to use a technical specification for the analysis and software of the SCADA system for the programming and the configuration of the displays in a SCADA environment.

The SA-RT analysis will allow an easy stage of a parametric modeling and implementation during the development of a control algorithm serving in the design of a supervising and monitoring system of the thermal power plant. Finally, this application of the functional analysis technique on the SCADA system of a TPP shows in brief the interests of the SA-RT method in the design of supervisory systems. 
From this case study of the SCADA system of the thermal power plant, work in progress is to develop a functional analysis based on a technique of specification and real time for the various control-command applications of a thermal power plant and Develop the various displays used for the supervision system.

\section{REFERENCES}

[1] A.Abdelhadi and L.Hayet Mouss, The use of artificial immune system algorithms in monitoring industrial, 6th International Conference on Sciences of Electronics, Technologies of Information and Telecommunications (SETIT), 2012.

[2] D. Bailey and E. Wright, Practical SCADA for Industry, Elsevier, 2003.

[3] K. L. Ronald, Securing SCADA Systems, Wiley Publishing, Inc. 2006.

[4] J. Wiles, Techno Security's Guide to Securing SCADA: A Comprehensive Handbook On Protecting The Critical Infrastructure, Elsevier, 2008.

[5] A. C. Bejan, M. Iacob and D. G. Andreescu, SCADA Automation System Laboratory, Elements and Applications, $7^{\text {th }}$ International Symposium on Intelligent Systems and Informatics (SISY), 2009, pp. 181-186.

[6] I. Morsi, M. El Deeb and A. El Zwawi, SCADA/HMI Development for a Multi Stage Desalination Plant, Conference on Future Computing, Service Computation, Cognitive, Adaptive, Content and Patterns, 2009, pp. 67-71.

[7] S. Reynard, O. Gomis, and I. Benítez, Pina, Flexible manufacturing cell SCADA system for educational purposes. Comput Appl Eng Educ 16, 2008.

[8] I. Fagarasan, S. St. Iliescu and N. Arghira, Advances in Power System Control, Proceedings of the $1^{\text {st }}$ Workshop on Energy, Transport and Environmental Control Applications, Targoviste, 2009, pp. 62-71.

[9] K. Munro, SCADA - A critical situation, Network Security. Issue 1: 4-6, 2008.

[10] S. Sahin, M. Ölmez, and Y. Isler, Microcontroller based experimental setup and experiments for SCADA education. IEEE Trans Educ 53, 2010, pp. 437-444.

[11] E.I. Gergely, Fl. Popenţiu-Vladicescu, H. Madsen, G.E. Mang, Z.T. Nagy, D. Spoială, A Procedure for PLC Programs Validation, SOFA2009, Romania, 2009, pp. 169-174.

[12] Glaa R., Lakhoua M.N., Methodology of Analysis and Design of a SCADA System, Conférence Internationale en Sciences et Technologies Electriques au Maghreb CISTEM, 3-6 Nov. 2014.

[13] Ben Hamouda M., Lakhoua M.N., Methodology of Operating Safety and Supervision of a Production System, Conférence Internationale en Sciences et Technologies Electriques au Maghreb CISTEM, IEEE, 3-6 Nov. 2014.

[14] J. Ben Salem, M.N. Lakhoua, L. El Amraoui, Analysis of a Braking System on the Basis of Structured Analysis Methods, International Journal of Advanced Computer Science and Applications, Vol.7, $\mathrm{N}^{\circ} 1$, 2016.

[15] M. Hamedi, R. Farahani and M. Husseini, A distribution planning model for natural gas supply chain: A case study, Energy Policy, Vol.37, (3), pp. 799-812, 2009.

[16] F. Eugenio and A. Berzosa, Modeling and forecasting industrial end-use natural gas consumption, Energy Economics. vol.29. Issue 4: 710-742, 2007.

[17] Rapport Annuel 2013, Société Tunisienne de l'Electricité et du Gaz (STEG), juillet 2014.

[18] P. Jaulent, Génie logiciel les méthodes : SADT, SA, E-A, SA-RT, SYSP-O, OOD, HOOD, Armand Colin, 1992.

[19] D. Tschirhart, Commande en temps réel : conception et mise en œuvre d'un exécutif multitâche, Dunod, Paris 1990.

[20] D.J. Hatley and I.A. Pirbhai, Stratégies de spécification des systèmes temps réel (SA-RT), Masson, Paris, France, 1991.
[21] F. Cottet, Systèmes temps réel de contrôle - commande, Dunod, Paris 2005.

[22] L. Urbain and B. Tondu, Robot controller specification using SART approach, Proceedings of the Third IEEE Conference on Control Applications, 1994, pp. 303-308.

[23] A. Benzina and M. Paludetto, Software Engineering Conference, 1997, pp. 249-258.

[24] A. Naoui, S. Bel Hadj Ali, L.-E. and M.N. Abdelkrim, Application of functional specification and operational safety conventional methods for a networked control system suitable qualitative analysis, STA, 2014.

[25] M.N. Lakhoua, M. Ben Hamouda, R. Glaa, L. El Amraoui, Contributions to the Analysis and the Supervision of a Thermal Power Plant, International Journal of Advanced Computer Science and Applications, Vol.7, $\mathrm{N}^{\circ} 1,2016$.

[26] R. Glaa, M.N. Lakhoua, L. El Amraoui, Using SA/RT method and SCADA for the analysis and the supervision of an hydrogen circuit, Journal of Electrical Engineering, Vol.16, Nº3, 2016.

[27] M.N. Lakhoua, M. Ben Hamouda, R. Glaa, L. El Amraoui, Structured Analysis and Modeling of a Supervisory Control And Data Acquisition in a Thermal Power Plant, International Journal of Information Technology and Electrical Engineering, Vol.5, Issue 1, February 2016.

[28] S. Lihua and J.A. Keane, Algorithmic aspects of hierarchical verification for SA/RT models, IEEE Int. Conf. on Computational Cybernetics and Simulation, vol.3, 1997, pp. 2252- 2257.

[29] R.B. France and J. Bruel, Using Integrated Formal and Informal Modeling Techniques to Analyze Software Requirements: A PetriNet/SART Case Study, 1996.

[30] M.N. Lakhoua, Systemic analysis of a supervisory control and data acquisition system, Journal of Electrical Engineering, vol.11, №1, 2011.

[31] M.N. Lakhoua, Application of SA-RT method to supervisory systems, Journal of Electrical Engineering, Politechnica Publishing House, vol.11, N², 2011.

[32] F. Jimenez, M. Courvoisier, A.Garcia, G. Munoz, N.Harchani, M. AlMohamed and D. Esteve, Tools and models for systems design and synthesis of MEMS based on asynchronous circuits, IEEE International Conference on Industrial Technology, pp: 64 - 69, 2000.

[33] L. Guillen, O. Niño Prieto and A. Aguila Jurado, An Approach of RealTime System for River Monitoring and Flood-Warning System in Puebla, Mexico, World Applied Programming, vol.3, Issue (8), pp. 328340, 2013.

[34] A. Naoui, S. Bel Hadj Ali, L. Afilal, M. Naceur, Influence of the Networked control system structure on the diagnosis system behavior, International Conference SETIT, 2012, pp. 537-542.

[35] M. Sahraoui, M. Salem, M. F. Khelfi, Self Tuning Fuzzy controller of nonlinear systems, International Conference SETIT, 2012, pp. 912-916.

[36] A. Abdelhadi, L. Mouss, The use of artificial immune system algorithms in monitoring industrial, International Conference SETIT, 2012, pp. 5055 .

[37] M.N. Lakhoua, Structured Analysis and Supervision Applied on Heavy Fuel Oil Tanks, Journal of Computer Science and Control Systems, vol.9, N 1 , May 2016.

[38] M.N. Lakhoua, J. Ben Salem, L. El Amraoui, Augmenting SADT with Respect to Timing Constraints, Formalization and Dependability Evaluation, International Journal of Scientific \& Engineering Research, Vol.7, Issue 8, August-2016.

[39] Ben Hammouda M., Lakhoua M.N., El Amraoui L., Dependability Evaluation and Supervision in Thermal Power Plants, International Journal of Electrical and Computer Engineering, Vol. 5, N5: October 2015.

[40] T. Medjeldi, D. Moreau, J. C. Morissette, A. Pouliot, F. Renaud, Smart acquisition of medical data, International Conference SETIT, 2012, pp. 589-593.

[41] M. El Brak, M. Essaaidi, Wireless sensor network in smart grid technology: Challenges and opportunities, International Conference SETIT, 2012, pp. 578-583.

\section{Creative Commons Attribution License 4.0 (Attribution 4.0 International, CC BY 4.0)}

This article is published under the terms of the Creative Commons Attribution License 4.0 https://creativecommons.org/licenses/by/4.0/deed.en_US 